\title{
A multidisciplinary study of a geothermal reservoir below Thisted, Denmark
}

\author{
Morten Leth Hjuler, Henrik Vosgerau, Carsten Møller Nielsen, Peter Frykman, Lars Kristensen, \\ Anders Mathiesen, Torben Bidstrup and Lars Henrik Nielsen
}

The first geothermal plant in Denmark was established in 1984 near the town of Thisted (Fig. 1). For nearly 30 years the plant has successfully produced $c .43^{\circ} \mathrm{C}$ hot water (surface temperature) from a highly permeable sandstone reservoir in the Late Triassic to Early Jurassic Gassum Formation and used the heat from the geothermal water for district heating. The $45^{\circ} \mathrm{C}$ hot water (formation temperature) is pumped up from a vertical production well, Thisted-2, from a depth of c. $1250 \mathrm{~m}$ and the cooled water $\left(c .12^{\circ} \mathrm{C}\right)$ is re-injected into the formation through a vertical injection well, Thisted-3, located $1.5 \mathrm{~km}$ east of the production well.

In order to increase the capacity of the plant the supplier of district heating, Thisted Varmeforsyning, plans to add a new well to the current configuration. In 2013 the Geological Survey of Denmark and Greenland was assigned the task to propose suitable sites for a new well. The sites will be proposed based on the quality, continuity and temperature of the reservoir(s) within the Gassum Formation. Three possible well sites (Thisted-5A-C) were considered (Fig. 1).

Well-log information and core-analysis data from four existing wells, Thisted-1-4, indicate significant variations in reservoir properties and spatial extent of the reservoir bodies within the Gassum Formation. In order to establish a robust

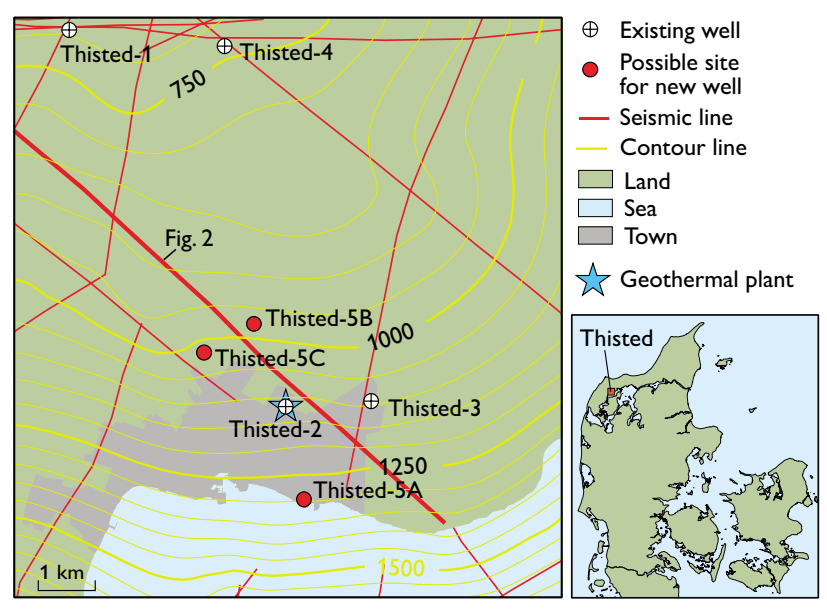

Fig. 1. Depth structure map of near top Gassum Formation (contour interval: $50 \mathrm{~m}$ ) of the Thisted area showing seismic lines, well locations and possible locations of the planned Thisted-5 wells. geological reservoir model that covers all reservoir-qualifying aspects it was decided to conduct the evaluation as a multidisciplinary study that included: (1) seismic interpretation and mapping, (2) determination of reservoir temperature, (3) petrophysical interpretation of well logs and (4) sedimentological description of well cores.

Two possible well configurations were considered: (1) The new Thisted- 5 is used as an injection well and Thisted- 2 continues as a production well. Production can be increased with additional injection capacity, and by using Thisted- 5 as the principal injection well the breakthrough of cold injection water is postponed. (2) The new Thisted-5 is used as a production well with Thisted-2 and -3 as injection wells. Thisted-5 will be located downflank of the Thisted salt structure and will produce geothermal water from greater depths and expectedly with higher temperature than the existing production well.

\section{Geological setting and seismic mapping}

Thisted is located in the central to northern part of the Norwegian-Danish Basin in an area characterised by numerous salt pillows and diapirs. The Upper Permian - Mesozoic suc-

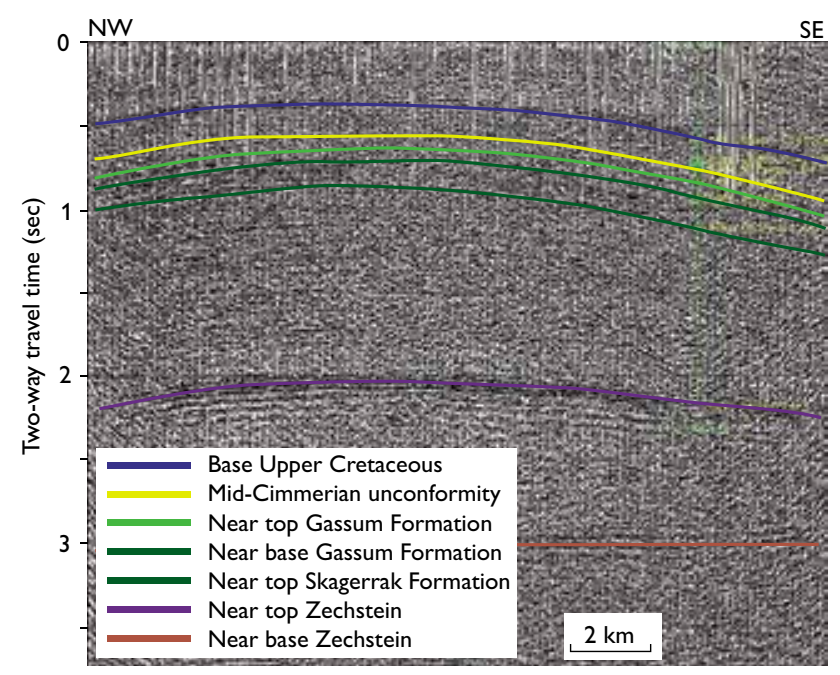

Fig. 2. Seismic section (PRKL7374A no 74249) across the Thisted salt pillow. 


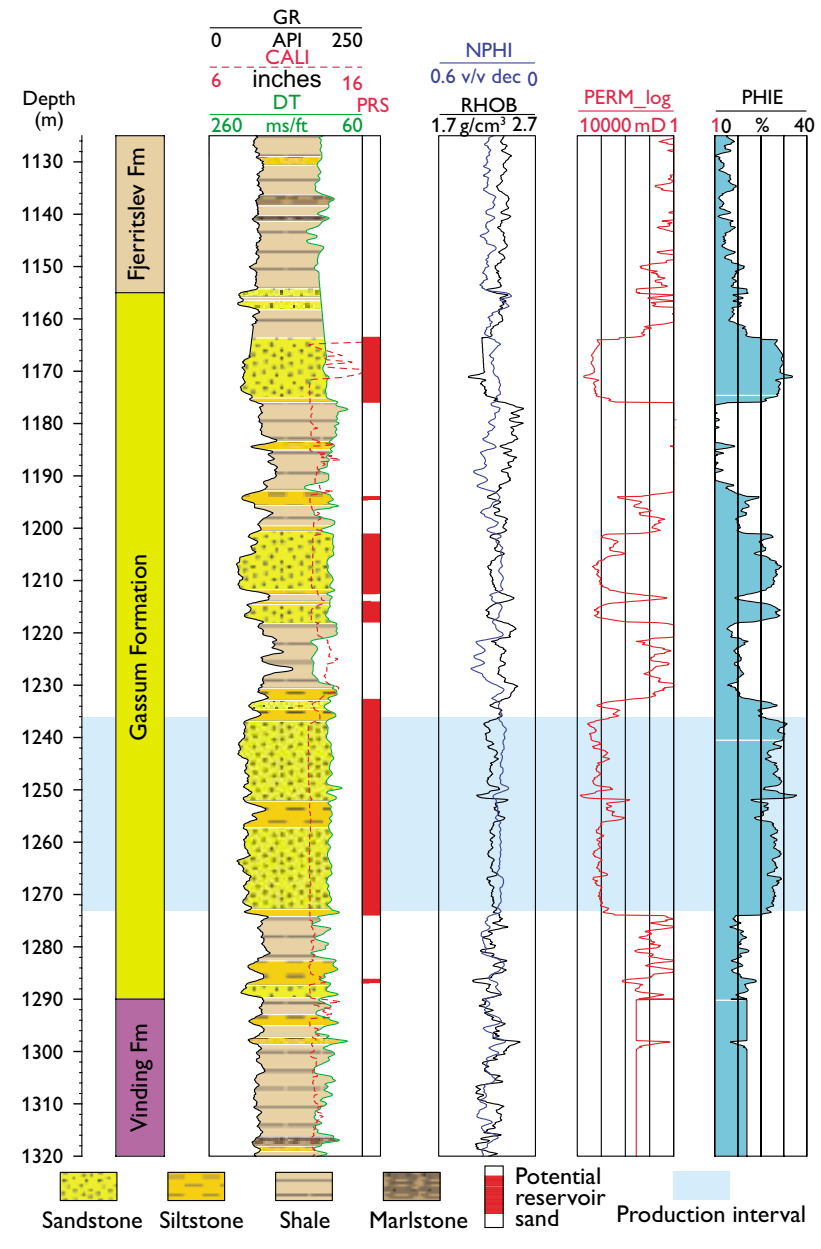

Fig. 3. Petrophysical evaluation of the Gassum Formation in the Thisted-2 well, including a lithological interpretation.

cession consists of $5-5.5 \mathrm{~km}$ of sediments (Vejbæk \& Britze 1994). Thick Zechstein salt layers are overlain by Triassic sandstone, mudstone, carbonate and salt, followed by Lower Jurassic mudstone, Middle Jurassic sandstone, Upper Jurassic - Lower Cretaceous mudstone and siltstone with few sandstone beds. This succession is overlain by thick layers of chalk and limestone.

Thisted is situated over the southern part of a gently sloping salt pillow and the strata above the salt pillow in the area of the Thisted- 2 and 3 wells dip towards the south. Thisted-1 and 4 are located on top of the structure.

All relevant 2D seismic profiles in the Thisted area were interpreted in order to map the presence and variations of the reservoirs including depth, changes in thickness and the occurrence of faults which may affect the lateral continuity of the reservoirs. Due to low resolution of the seismic data

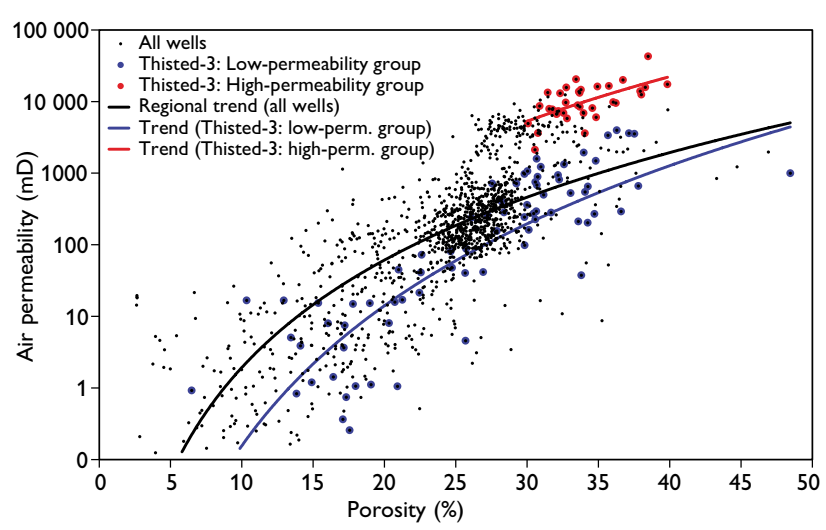

Fig. 4. Porosity-permeability plot based on conventional core analysis data from the Gassum Formation.

near the potential sites of Thisted-5, it was difficult to map faults and lateral changes in lithology and to trace seismic horizons. However, seven horizons could be identified, including the near top and near base of the Gassum Formation (Fig. 2). Mapping of single reservoir intervals within the Gassum Formation was impossible and no faults were identified.

Based on the seismic interpretation, four depth structure maps were compiled, including one of the near Top Gassum Formation (Fig. 1). From this map the depth of the Gassum Formation at the three suggested well sites can be estimated. Relative to the Thisted-2 well, the Thisted-5A site is located downflank of the Thisted structure whereas the Thisted5B and 5C are situated upflank. Due to deeper burial and expected higher temperature of the geothermal target, the Thisted-5A site is suitable as a production well, whereas Thisted-5B and 5C are injection well candidates.

\section{Reservoir temperature}

Temperature data from Danish onshore wells are limited and include values from different depths and different formations, thus the geothermal gradient covers a wide range of $28-20^{\circ} \mathrm{C} / \mathrm{km}$. In the Thisted-2 production well, c. $43^{\circ} \mathrm{C}$ warm water (surface temperature) is produced from a depth of $1250 \mathrm{~m}$ (formation temperature $45^{\circ} \mathrm{C}$ ). The geothermal target in Thisted-5A is estimated to be located at a depth of c. $1450 \mathrm{~m}$, which corresponds to a temperature up to $52^{\circ} \mathrm{C}$, if extrapolated from a continuation of the regional gradient and the temperature data from the Thisted- 3 well. The geothermal target in the Thisted-5B and 5C injection sites is located at a depth of $c .1150 \mathrm{~m}$ corresponding to a reservoir temperature of $41^{\circ} \mathrm{C}$ using Thisted-3 data. 
Table 1. Reservoir parameters for net sand from the Gassum Formation*

\begin{tabular}{lccccccc}
\hline $\begin{array}{l}\text { Well } \\
\text { no. }\end{array}$ & $\begin{array}{c}\text { Formation } \\
\text { thickness }(\mathrm{m})\end{array}$ & $\begin{array}{c}\text { Gross sand } \\
\text { thickness }(\mathrm{m})\end{array}$ & $\begin{array}{c}\text { Net sand } \\
\text { thickness }(\mathrm{m})\end{array}$ & $\mathrm{N} / \mathrm{G}^{\dagger}$ & $\begin{array}{c}\text { Average } \\
\text { porosity }(\%)\end{array}$ & $\begin{array}{c}\text { Estimated } \\
\text { gas perm. }(\mathrm{mD})\end{array}$ & $\begin{array}{c}\text { Estimated } \\
\text { reservoir perm. }(\mathrm{mD})^{\ddagger}\end{array}$ \\
\hline Thisted-1 & 137 & 94.4 & 84.4 & 0.62 & 28.3 & 2500 & 3125 \\
Thisted-2 & 135 & 94.9 & 70.3 & 0.52 & 25.3 & 1300 & 1625 \\
Thisted-3 & 115 & 67.4 & 54.5 & 0.47 & 28.6 & 3500 & 4375 \\
Thisted-4 & 114 & 36.6 & - & - & - & - & - \\
\hline
\end{tabular}

* Shale and porosity cut-off applied, net sand is defined as sandstone with $<30 \%$ shale and porosity $>15 \%$.

${ }^{\dagger} \mathrm{N} / \mathrm{G}$ : net sand thickness divided by formation thickness.

* Estimated reservoir permeability: estimated gas permeability multiplied by 1.25 (upscaling factor).

\section{Well-log interpretation and core description}

The evaluation of the reservoir quality of the Gassum Formation is primarily based on wireline logs and core-analysis data from Thisted-1-4 (Fig. 3). The quality of the logs is fairly good, but at certain intervals indications of caving lead to uncertain porosity estimates. Lithology, clay content, porosity and permeability are evaluated from combined analyses of $\log$ data, lithological descriptions of cores and core analysis data.

High, well test-based, porosities and permeabilities for the Thisted wells were validated by gas permeability measurements from core analysis and are possibly caused by the relatively shallow depth of the Gassum Formation (Hjuler et al. 2013). The regional porosity-permeability trend (Fig. 4) significantly underestimates the actual (well test) permeability and was therefore calibrated to more closely approximate the well test results. Evaluation of the sandstones indicates high average porosities exceeding $28 \%$ for the Thisted- 1 and 3 wells (Table 1). The interpreted porosity of $25.3 \%$ for the Thisted-2 well seems too low considering the fairly high test permeability of $3670 \mathrm{mD}$; this is possibly due to erroneous $\log$ data. Despite considerable variation of the assessed net sand thickness within the study area all thicknesses are considered sufficient for geothermal exploitation (Table 1).

Detailed sedimentological descriptions and interpretations of the cores from the Thisted-3 well indicate that the reservoir sandstones were mainly deposited in fluvial and estuarine environments (Nielsen 2003; Hjuler et al. 2013). Considerable lateral and stratigraphical variations of the logs from the Thisted wells indicate spatial and temporal variations of the sedimentary environment, which must have a significant influence on reservoir distribution and quality. It is thus important for the mapping of reservoir intervals to

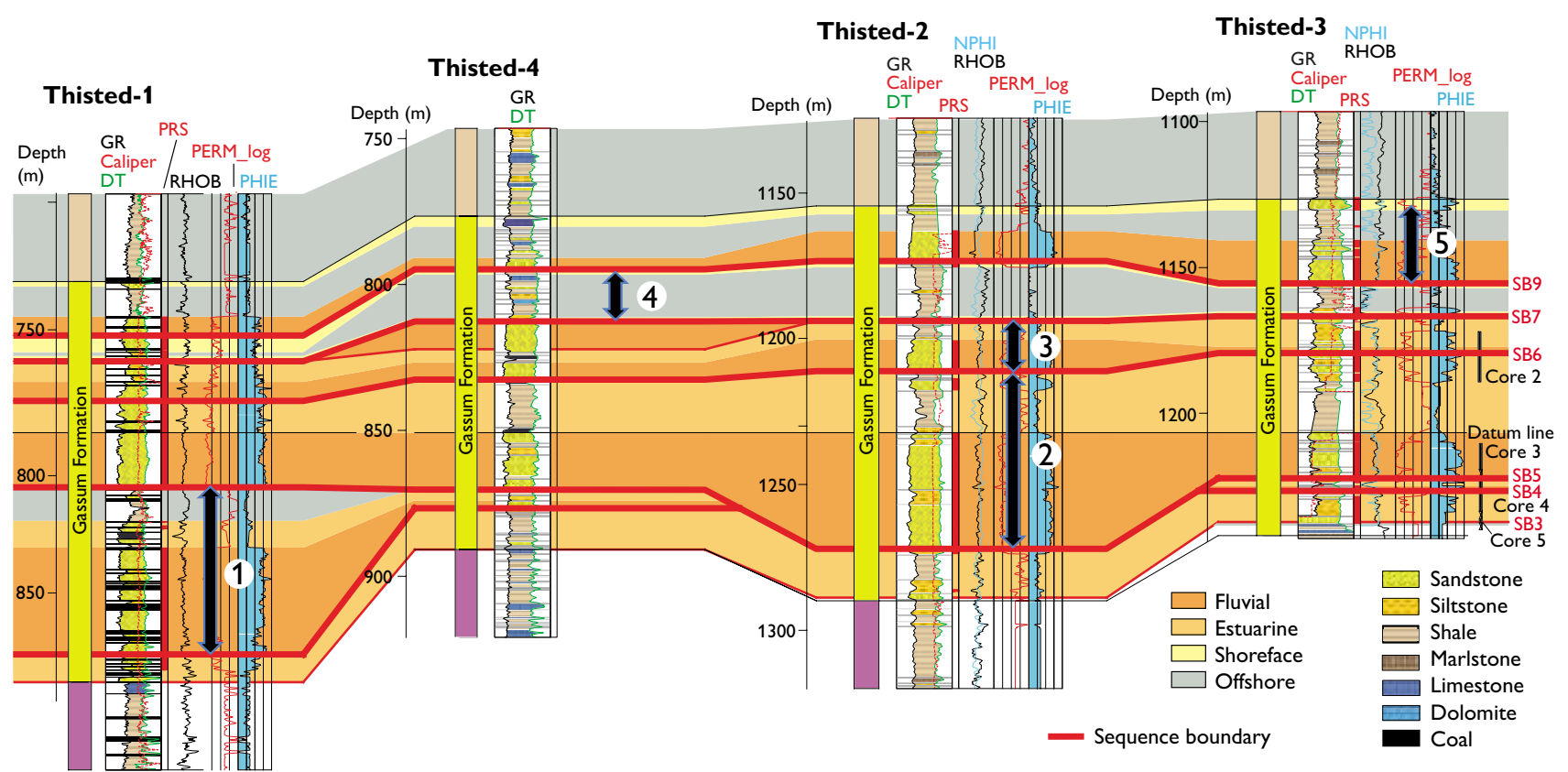

Fig. 5. Log correlation of sedimentary units within the Gassum Formation in the four Thisted wells. 1-5: sequences, red lines: sequence boundaries (corresponding to incised valley floors), PRS: potential reservoir sand. The sediments of the incised valleys are fluvial and estuarine. 


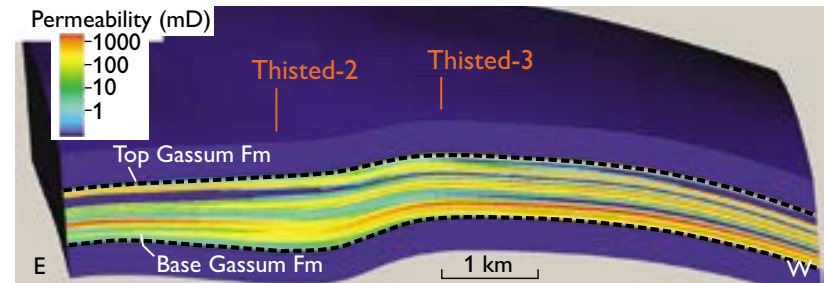

Fig. 6. Permeability model that crosses the Thisted-2 and 3 wells.

understand the variations in the sedimentary environment. Hence the logs of the four wells have been correlated (Fig. 5).

Five periods of sea-level rises and falls were identified within the Gassum Formation. During sea-level falls, incised valleys formed which were filled with fluvial and estuarine sediments during subsequent rises in sea level. The extent of reservoir sandstone deposits is limited by the extent of the valleys. To estimate the dimensions of sandstone bodies in the Thisted area the extent of present-day estuaries has been studied. It was found that the width of estuarine sediment bodies exceeds $8 \mathrm{~km}$ and the lengths are probably several tens of kilometres. In the Late Triassic - Early Jurassic the overall shoreline was NW-SE oriented. The seismic data do not allow the determination of the relief and extent of the incised valleys, but an overall NE-SW-orientation of the estuarine sediment bodies is assumed.

The reservoir lithology is limited to fluvial and estuarine sandstones with the fluvial sandstones being $c$. 20 times more permeable than the estuarine sandstones because detrital clay clogs the pores of the latter. As expected, the reservoir properties of clay- and siltstones outside the estuaries are poor and thus fluvial sandstones in the valleys may be hydraulically separated from each other. Log correlation implies that the estuarine deposits may coalesce into larger reservoir units, or may be partly separated by layers of low permeability. In a more landward position towards the NE fluvial reservoir sandstones may amalgamate into more coherent reservoir units, leading to improved reservoir continuity.

\section{A reservoir model}

Petrel $^{\circledR}$ software was used to establish a reservoir model that covers an area of $11 \times 13.5 \mathrm{~km}$; flow simulations and dynamic modelling were performed using the Eclipse ${ }^{\oplus} 100$ software (Fig. 6). Input data for the reservoir model were prepared by integration of interpreted seismic data, depth structure maps, temperature assessment, petrophysical evaluation, core description and log correlations as described above.
Comparison with historic data was not possible as no pressure data of the Thisted-2 and 3 wells are available; the simulated response from the dynamic modelling could only be adjusted because no significant temperature drop has been recorded in the production water since 1984 . Hence the model results are uncertain and should be evaluated with caution due to lack of calibration data. With this limitation in mind, and using the current well configuration, the model simulations indicate another 15 years of production with no alarming decrease in water temperature (less than $1^{\circ} \mathrm{C}$ ).

With Thisted-5A as a new production well situated downflank of the existing well pair, the production could benefit from a higher temperature with no sign of cooler water arriving during an operational time of 30 years (uncertainty in modelling results as above). With Thisted-5B or $-5 \mathrm{C}$ as a new injection well situated at shallower depth than the existing well pair, and with Thisted-2 still used as production well, the new injection well can benefit from higher permeability.

\section{Concluding remarks}

By integrating data from geological, geophysical and petrophysical disciplines, a detailed geological model was established that provides a structural framework and demonstrates how depositional environment controls the lateral extent, continuity and quality of reservoirs. A detailed reservoir model was also established, which can simulate the remaining lifetime of the geothermal plant with the current well configuration, or the lifespan of the plant with the addition of a new production or injection well. The combination of geological and reservoir models provides indications of the best sites for additional production or injection wells.

\section{References}

Hjuler, M.L., Vosgerau, H., Nielsen, C.M., Frykman, P., Kristensen, L., Mathiesen, A., Bidstrup, T. \& Nielsen, L.H. 2013: Assessment of potential capacity increase of the geothermal plant at Thisted by adding a new geothermal well. Danmarks og Grønlands Geologiske Undersøgelse Rapport 2013/80, 90 pp.

Nielsen, L.H. 2003: Late Triassic - Jurassic development of the Danish Basin and Fennoscandian Border Zone, southern Scandinavia. In: Ineson, J.R. \& Surlyk, F. (eds): The Jurassic of Denmark and Greenland. Geological Survey of Denmark and Greenland Bulletin 1, 459-526.

Vejbæk, O.V. \& Britze, P. 1994: Geological map of Denmark 1:750 000. Top pre-Zechstein (two-way traveltime and depth). Danmarks Geologiske Undersøgelse Kortserie 45, 8 pp.

Authors' address
Geological Survey of Denmark and Greenland, ØsterVoldgade 10, DK-1350 Copenhagen K, Denmark; E-mail: mlh@geus.dk 